\title{
COMUNICAÇÃO
}

\section{ALTERAÇÕES QUÍMICAS, FÍSICAS E FÍSICO-QUÍMICAS DA TANGERINAPONKAN (Citrus reticulata Blanco) DURANTE O ARMAZENAMENTO REFRIGERADO}

\author{
Chemical, physical and physical-chemical changes on tangerina 'ponkan' \\ (Citrus reticulata Blanco) under refrigerated storage
}

\author{
Adriana Aparecida Souza Vale ${ }^{1}$,Custódio Donizete dos Santos², Celeste Maria Patto de Abreu \\ Angelita Duarte Corrêa ${ }^{4}$, Juliana Araújo Santos ${ }^{5}$
}

\begin{abstract}
RESUMO
O objetivo proposto neste trabalho foi o de avaliar as alterações químicas, físicas e físico-químicas da tangerina 'Ponkan' (citrus reticulata Blanco) durante o armazenamento refrigerado a $5 \pm 2{ }^{\circ} \mathrm{C}$ e umidade relativa de $85 \pm 3 \%$ por um período de 28 dias, em dois estádios de maturação (frutos coletados no início da safra; com a casca mais verde e frutos coletados no final da safra com a casca amarela). Os frutos foram coletados com pedúnculo, ao acaso de um pomar comercial com sete anos de idade, localizado no município de Perdões, região Sul do Estado de Minas Gerais. Foram realizadas duas colheitas, uma no mês de Abril quando os frutos estavam com a casca verde, mas já estavam aptos para o consumo; e outra mais no final da safra no mês de Julho quando os frutos já estavam com a casca bem amarela. Os frutos coletados foram levados ao Laboratório de Bioquímica da Universidade Federal de Lavras, onde foram selecionados 100 (cem) frutos de tamanho uniforme e com ausência de injúrias a cada colheita, estes foram lavados com uma solução de hipoclorito de sódio a $1 \%$, protocolados, pesados, medidos e realizadas as leituras de cor. Os frutos foram então armazenados em refrigerador a $5 \pm 2^{\circ} \mathrm{C}$ e umidade relativa de $85 \pm 3 \%$ por um período de 28 dias, e as análises foram realizadas nos frutos e no suco dos frutos aos $0,714,21$ e 28 dias de armazenamento. O delineamento experimental utilizado foi o inteiramente casualizado com 5 repetições de 4 frutos . Os resultados mostraram que quase todas as análises realizadas apresentaram variações significativas.

A perda de massa, os diâmetros transversais e longitudinais apresentaram diminuições significativas com os dias de armazenamento refrigerado. Os açúcares também tiveram variações significativas com tendência de aumento com os dias de armazenamento. $\mathrm{O}$ pH não apresentou variações significativas. Os teores de Vitamina $\mathrm{C}$ não apresentaram variações significativas com os dias de armazenamento refrigerado. A coloração da casca dos frutos foi medida com um colorímetro e foram medidos três variáveis de cor: luminosidade, teor de amarelo e teor de vermelho. Pode-se observar visualmente que os frutos coletados no início da safra apresentaram um ressecamento das vesículas de suco, ou seja, frutos com granulação, principalmente a partir da segunda semana de armazenamento, enquanto os frutos coletados mais maduros com maiores teores de açúcares solúveis foram mais resistentes ao ressecamento interno das vesículas.(análise visual e tátil).
\end{abstract}

Termos para indexação: Ponkan, alterações químicas, refrigeração, pós-colheita.

\section{ABSTRACT}

This work was aimed to evaluating chemical, physical and physical-chemical changes on tangerine 'Ponkan' (citrus reticulata Blanco) during the storage at $5 \pm 2{ }^{\circ} \mathrm{C}$ under relative humidity of $85 \pm 3 \%$, for a period of 28 days, in two maturation stadiums (fruits collected at the beginning of the crop; with the greenest peel and yellow peel fruits,, collected by the end of the crop). Fruits with stalf were alleatory collected in a seven-years old commercial orchard, located at Perdões, South area of the State of Minas Gerais. Fruits were collectd twice: on April, when they got a green peel, but they were already edible; and on July, by the end of the crop, when fruits got a very yellow peel. Then fruits were taken to the Laboratory of Biochemistry of the Federal University of Lavras, where a hundred aff them with uniform size and injury were washed with a $1 \%$ sodium hypochoride solution, marked, weigthted measured and submitted to color readings. After 0,7,14,21 and 28 days in a refrigerator at fruits of uniform size and with absence of offenses to each crop, these were washed with a hipoclorito of sodium solution to $1 \%$, recorded, heavy, measured and accomplished the color readings. Then the fruits were stored then in refrigerator at $5 \pm 2^{\circ} \mathrm{C}$, under relative humidity of $85 \pm 3 \%$, fruits as well as thein juice were analysed. The experimental outline used was entirely randomized, with five replicates containig four fruits in each one. Almost all rescelts were significantly dependent on the number of storage days. Loss and traverse and longitudinal diameter presented significant decreases as the number the of refrigerated storage days increased. Sugar concentration also had significant variations, increasing with storage. $\mathrm{pH}$ and vitamin $\mathrm{C}$ did not present significant variations. Fruit pell coloration was measured in a color imeter using there colour variables: brightness, yellow and red intensity. Cold be observed visuallty that fruits collected in the beginning of the crop, specially those with granulation, aftem one week of storage, presented juice vesicles dried, while fruits collected riper, with larger amounts of soluble sugars, were more resistant inernal drying of vesicles (visual and tactile analysis).

Index terms: Ponkan, Refrigeration, chemical alterations, post harvest.

(Recebido para publicação em 5 de maio de 2003 e aprovado em 6 de janeiro de 2005)

\footnotetext{
'Licenciada em Química, M.Sc. Departamento de Química/DQI - Universidade Federal de Lavras/UFLA - Cx. P. 3037 - $37.200-000$ - Lavras, MG adrianasouzavale@yahoo.com.br

2DS, Professor Titular do Departamento de Química/DQI - Universidade Federal de Lavras/UFLA - Cx. P. 3037 - $37.200-000$ - Lavras, MG.

${ }^{3}$ DS, Professora Adjunta do Departamento de Química/DQI - Universidade Federal de Lavras /UFLA- Cx. P. 3037 - 37.200-000 - Lavras, MG.

${ }^{4}$ DS, Professora Adjunta do Departamento de Química/DQI - Universidade Federal de Lavras /UFLA- Cx. P. 3037 - 37.200-000 - Lavras, MG.

${ }^{5}$ Aluna da graduação do curso de Agronomia - Universidade Federal de Lavras /UFLA.
} 
O Brasil é o maior produtor mundial de citros, e as tangerines constituem o segundo grupo de cítricos mais importantes na citricultura mundial, ocupando a maior faixa de adaptação climática entre os cítricos cultivados, uma vez que são plantas igualmente tolerantes a níveis altos e baixos de temperatura ambiente (FIGUEIREDO, 1991).

A tangerina 'Ponkan' apresenta grande aceitação por parte do consumidor devido a vários aspectos, tais como a coloração acentuada, o sabor doce, o fácil descascamento e o tamanho do fruto que é mais expressivo que o das demais, normalmente encontradas no mercado (FIGUEIREDO, 1991).

A conservação pós-colheita é de grande importância para que frutas e hortaliças cheguem ao consumidor sem alterações em seu valor nutritivo, aspecto e gosto. Para tanto, o processo de conservação deve partir de produtos com boa qualidade na colheita e colhidos no grau de maturação adequado a cada espécie. É preciso ainda, conhecer a resistência de cada produto ao armazenamento refrigerado (EMBRAPA, 2002). O adequado armazenamento dos frutos permite também ampliar o período de comercialização e consumo, constituindo-se em maior segurança de venda, geralmente com vantagens financeiras.

O objetivo proposto neste trabalho foi o de avaliar as alterações químicas, físicas e físico-químicas dos frutos da tangerina 'Ponkan', em duas épocas de colheita (início e final da safra), durante o armazenamento refrigerado a $5 \pm 2^{\circ} \mathrm{C}$ e $85 \pm 3 \%$ de umidade relativa.

Os frutos foram coletados, ao acaso, pela manhã, em um pomar comercial com sete anos de idade, localizado no município de Perdões / MG. A cidade possui as seguintes coordenadas: $21^{\circ} 05^{\prime} 50$ "de latitude Sul (distância do equador ao sul), $45^{\circ} 05^{\prime} 50^{\prime \prime}$ de longitude oeste (distância do meridiano de Greenwich, a oeste) e 767 metros de altitude. O solo predominante é o latossolo vermelho-amarelo. Os frutos foram coletados em duas épocas no início da safra mês de Abril (frutos com a casca mais verde) e no final da safra na região mês de Julho (frutos com casca amarela). Os frutos foram colhidos com pedúnculo e levados ao laboratório de Bioquímica do departamento de Química da Universidade Federal de Lavras, onde foram selecionados 100 frutos a cada época de colheita para compor a parcela experimental. O experimento seguiu o delineamento inteiramente casualizado, em esquema fatorial $(2 \times 5) \times 2$ com parcelas sub-divididas no tempo, sendo duas épocas de colheita (início e final da safra), cinco épocas de armazenamento refrigerado( $0,7,14,21$,e 28 dias a $5 \pm 2^{\circ} \mathrm{C}$ e $85 \pm 3 \%$ de umidade relativa) e cinco repetições com 4 frutos cada. $\mathrm{O}$ programa estatístico utilizado foi o Sisvar®.

A determinação da cor foi realizada na casca dos frutos, utilizando-se um colorímetro digital da marca Minolta modelo CR 300. Foram realizadas 3 leituras de cor na escala tridimensional $\mathrm{L}^{*} \mathrm{a} * \mathrm{~b} *$, em que $\mathrm{L} *$ indica a luminosidade, $a^{*}$ indica o teor de vermelho e $b^{*}$ indica o teor de amarelo. As leituras foram feitas em regiões distintas na região equatorial de cada fruto por ser uma área mais homogênea.

A perda de massa (gramas) foi determinada fazendose a diferença entre a massa inicial dos frutos e aquela obtida a cada dia de análise, com auxílio de balança eletrônica Precision com três casas decimais. Os diâmetros transversais e longitudinais (centímetros) foram medidos com o auxílio de um paquímetro.

As análises físico-químicas foram realizadas no suco, após a sua homogeneização, e constaram das seguintes variáveis: $\mathrm{pH}$, medido com potenciômetro digital (AOAC, 1992); acidez total titulável (\% de ácido cítrico/100 mL de suco), determinada por titulometria com solução de hidróxido de sódio 0,1 N (INSTITUTO ADOLFO LUTZ, 1985).

Os sólidos solúveis totais foram determinados no suco por leitura direta, utilizando-se um refratômetro digital Palette (Atago Co, LTD, Japão), modelo PR 100, com compensação de temperatura automática, e os resultados foram expressos em porcentagem, conforme normas da AOAC (1992).

A extração dos açúcares solúveis redutores e nãoredutores foi obtida, utilizando-se o método Lane-Enyon, citado pela AOAC (1992). O extrato foi obtido homogeneizando-se manualmente $10 \mathrm{~mL}$ de suco com $50 \mathrm{~mL}$ de Etanol a $95 \%$ e deixado em repouso para a extração por 23 horas. No dia seguinte, a suspensão foi colocada em agitador por 60 minutos e filtrada em papel filtro. O filtrado obtido aproximadamente $80 \mathrm{~mL}$, foi evaporado até a obtenção de um volume de aproximadamente $5 \mathrm{~mL}$ e completado para $50 \mathrm{~mL}$ com água destilada, constituindo -se o extrato para as análises de açúcares redutores, não-redutores e solúveis totais. Os açúcares redutores foram determinados pelo método descrito por Noelting \& Bernfeld (1984), utilizando o ácido 3,5 dinitrosalić́lico (DNS). O Teor de sacarose foi obtido pela diferença entre os teores de açúcares totais e o teor de açúcares redutores, multiplicando o resultado pelo fator 0,95 (fator de conversão dos monossacarídeos glicose e frutose no dissacarídeo sacarose). Os resultados foram expressos em gramas por 100 mililitros de suco $(\mathrm{g} / 100 \mathrm{~mL})$. 
A extração da vitamina $C$ foi realizada a partir de 5 $\mathrm{mL}$ de suco, onde foram adicionados $50 \mathrm{~mL}$ de ácido oxálico $0,5 \mathrm{~g} / 100 \mathrm{~mL}$, juntamente com uma pequena quantidade de kielssegur para retirar os interferentes. A quantificação da vitamina $\mathrm{C}$ foi feita pelo método espectrofotométrico, conforme a técnica descrita por Stroecker \& Henning (1967) e os resultados foram expressos em $\mathrm{mg} / 100 \mathrm{~mL}$ de suco.

Os resultados das determinações da luminosidade estão apresentados na Figura 1. A luminosidade diminuiu com o armazenamento refrigerado para as duas épocas de colheita, provavelmente devido a desidratação, que deixou os frutos mais opacos e sem brilho. A colheita inicial apresentou menor luminosidade $(39,22)$ do que a colheita final $(78,89)$, fato que pode estar associado a coloração dos frutos; na colheita inicial a casca era de cor bem mais verde enquanto que na colheita final eles apresentavam coloração bem amarela, portanto uma maior luminosidade está associada com a casca amarela.

Os resultados dos teores de vermelho encontram se na Figura 2. Os teores de vermelho variaram muito pouco com a refrigeração e apresentaram um comportamento semelhante para as duas colheitas. Entre elas a colheita inicial apresentou valores negativos para os teores de vermelho $(-9,85)$ e positivos $(30,78)$ para a colheita final quando os frutos estavam aparentemente com coloração bem alaranjada.
Os resultados dos teores de amarelo encontram-se na Figura 3. Os frutos da colheita inicial apresentaram valores menores que os frutos da colheita final. Esse resultado está provavelmente associado a coloração aparente dos frutos no final da colheita ser bem alaranjada. Com o armazenamento refrigerado observa-se uma pequena diminuição no teor de amarelo dos frutos. Devese salientar que a cor amarela dos frutos da tangerina 'Ponkan"é um excelente atrativo para os consumidores, entretanto, por serem frutos não climatéricos, os frutos maduros porém com a cor da casca ainda verde, apresentam atributos de qualidade semelhante aos frutos verdes (CHITARRA, 1994).

Os resultados da perda de massa dos frutos durante o armazenamento refrigerado encontram-se na Figura 4. As perdas aumentam com o armazenamento refrigerado para as duas colheitas, devido principalmente à desidratação. Entretanto, os frutos da colheita inicial, mais verdes, foram mais resistentes ao armazenamento refrigerado por apresentaram menor perda de massa e esta estar diretamente relacionada com a perda de água. Embora tenha havido uma menor perda de água, dos frutos mais verdes da colheita inicial, eles apresentaram ressecamento das vesículas de suco (observação visual), principalmente a partir de 14 dias de armazenamento refrigerado.

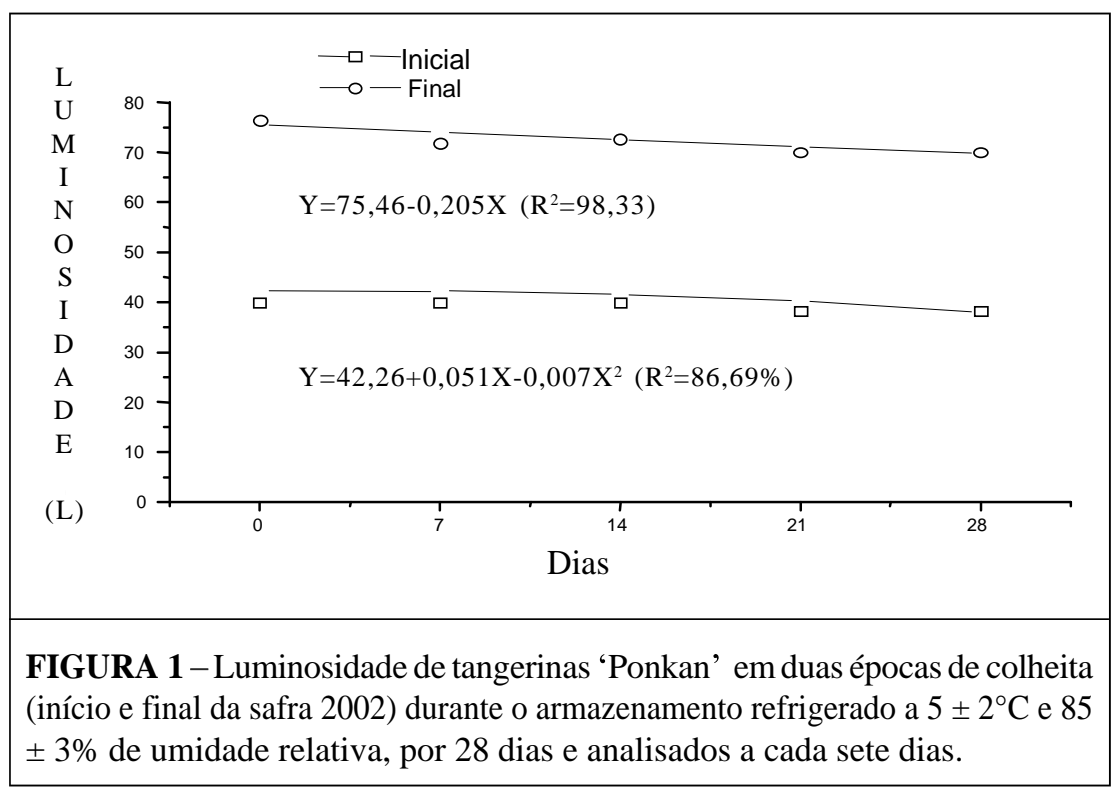

Ciênc. agrotec., Lavras, v. 30, n. 4, p. 778-786, jul./ago., 2006 


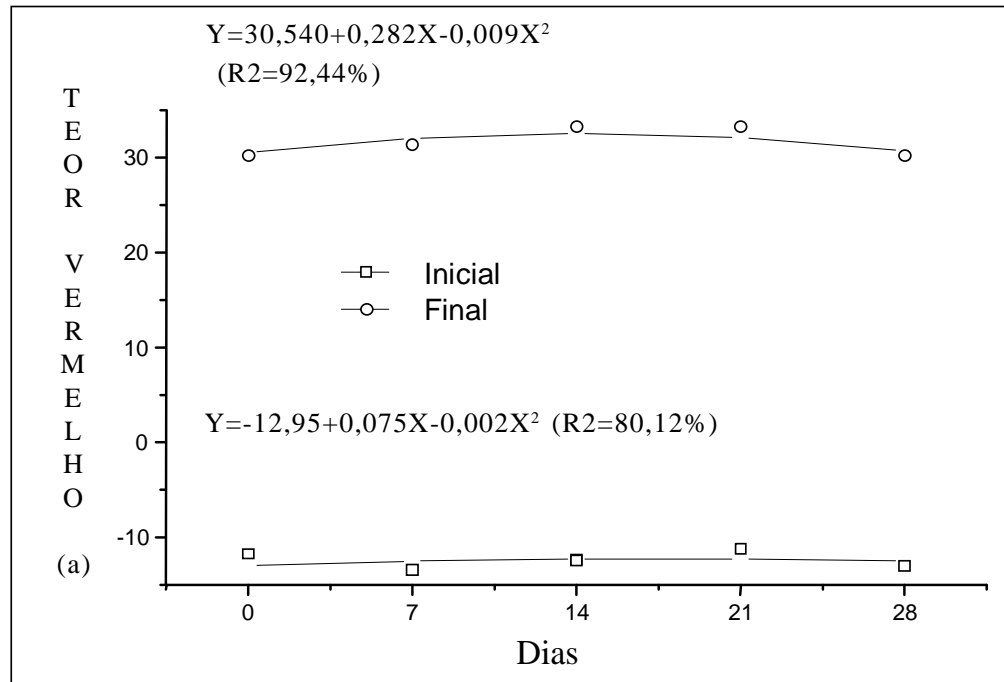

FIGURA 2 - Teor Vermelho de tangerinas 'Ponkan' coletadas em duas épocas de colheita (início e final da safra 2002) durante o armazenamento refrigerado a $5 \pm 2^{\circ} \mathrm{C}$ e $85 \pm 3 \%$ de umidade relativa, por 28 dias e analisados a cada sete dias.

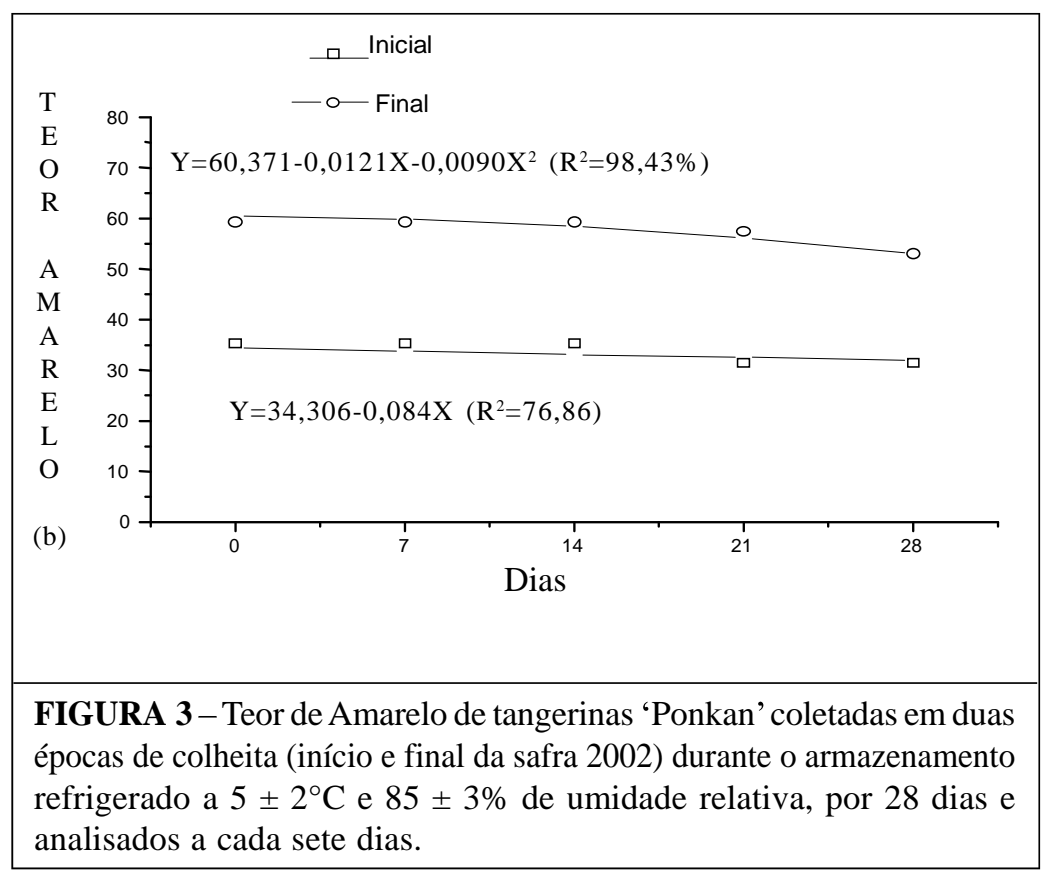

Ciênc. agrotec., Lavras, v. 30, n.4, p. 778-786, jul./ago., 2006 


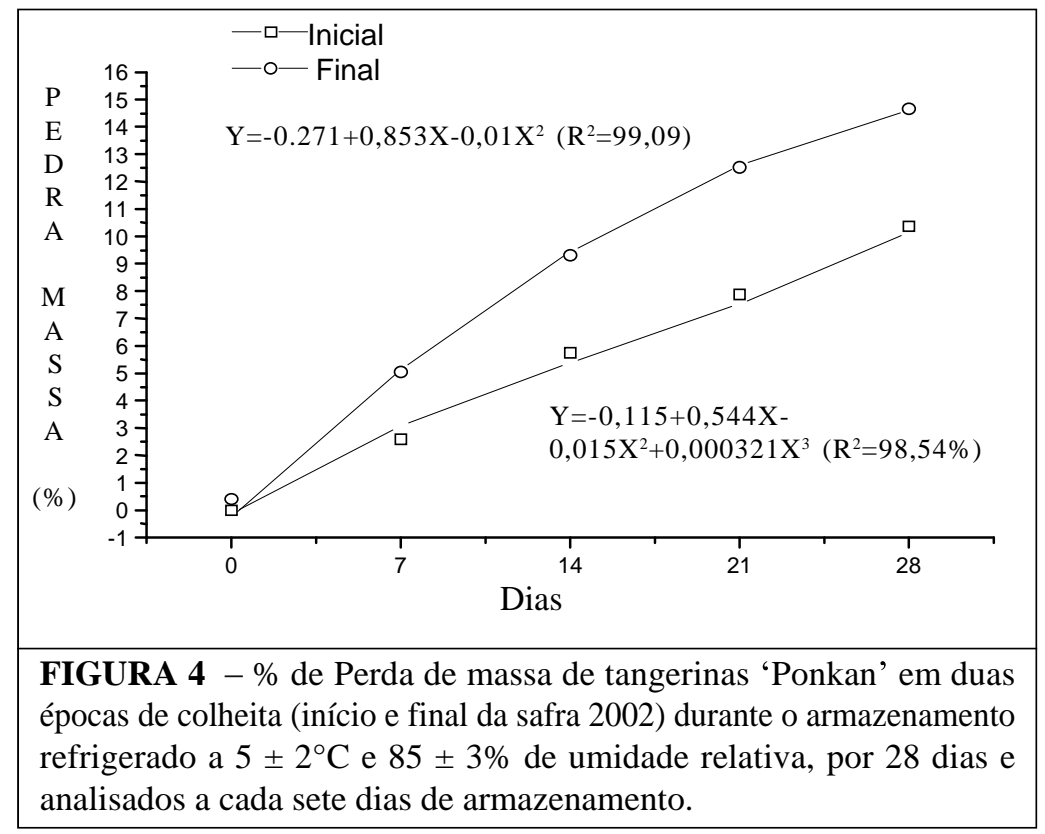

Os frutos da colheita final, mesmo com maior perda de água, não apresentaram ressecamento das vesículas de suco. A explicação para este ressecamento das vesículas de suco não foi determinada, mas pode estar relacionadas com uma maior quantidade de polímeros não hidrolizados nas vesículas de suco, como, por exemplo as pectinas. Embora as tangerinas sejam frutos não climátericos, muitas transformações devem ocorrer durante a maturação dos frutos na planta (KOLLER, 1994).

A perda de massa se relaciona à perda de água, causa principal da deteriorização, pois resulta não somente em perdas quantitativas mas também na aparência (murchamento e enrugamento), nas qualidades texturais (amaciamento, perda da frescura e suculência) e na qualidade nutricional (KADER, 1992).

Os resultados dos diâmetros longitudinais e transversais estão apresentados nas Figuras 5 e 6, respectivamente. A diminuição dos diâmetros com o armazenamento refrigerado era uma observação esperada uma vez que a perda de massa é acentuada nas duas colheitas. Os diâmetros transversais dos frutos da colheita inicial foram menores que para os frutos da colheita final durante todos os dias de armazenamento refrigerado, mostrando que ainda há desenvolvimento do fruto na planta com o amadurecimento. (Figura 4).

Os resultados da acidez total titulável (ATT) encontram-se na Figura 7. Os frutos da colheita inicial apresentam maior teor de acidez que os frutos da colheita final, ou seja, os frutos mais verdes são normalmente mais ácidos, mesmo os frutos não climatéricos (REIS, 2000). Os índices de maturidade comercial baseiam-se em parâmetros internos e, um desses índices é a diminuição da acidez (TING \& ATTAWAY, 1971).

Durante o armazenamento refrigerado, a acidez total titulável diminuiu nas duas colheitas, sugerindo a utilização de ácidos orgânicos pelo fruto, principalmente nos frutos verdes (colheita inicial) onde o teor de açúcares solúveis é menor (resultados não apresentados). Nos frutos maduros (colheita final) com maiores teores de açúcares solúveis, a acidez total titulável (ATT) permanece constante até o $14^{\circ}$ (décimo quarto) dia de armazenamento e diminui até o final do armazenamento da mesma maneira que os frutos verdes. Essa estabilidade na acidez total titulável (ATT) deve estar associado ao maior conteúdo de açúcares solúveis que são predominantemente utilizados como substrato respiratório do fruto (ULRICH, 1970).

Valores do $\mathrm{pH}(3,7)$ não variaram com a refrigeração e com as épocas de colheita, embora houve diminuição da acidez total titulável (ATT) para esses dois parâmetros analisados (Figura 7). Deve-se salientar que os valores de $\mathrm{pH}$ podem variar diferentemente da acidez total titulável (ATT) em função do efeito tamponante dos ácidos orgânicos (CHITARRA \& CHITARRA, 1990). 

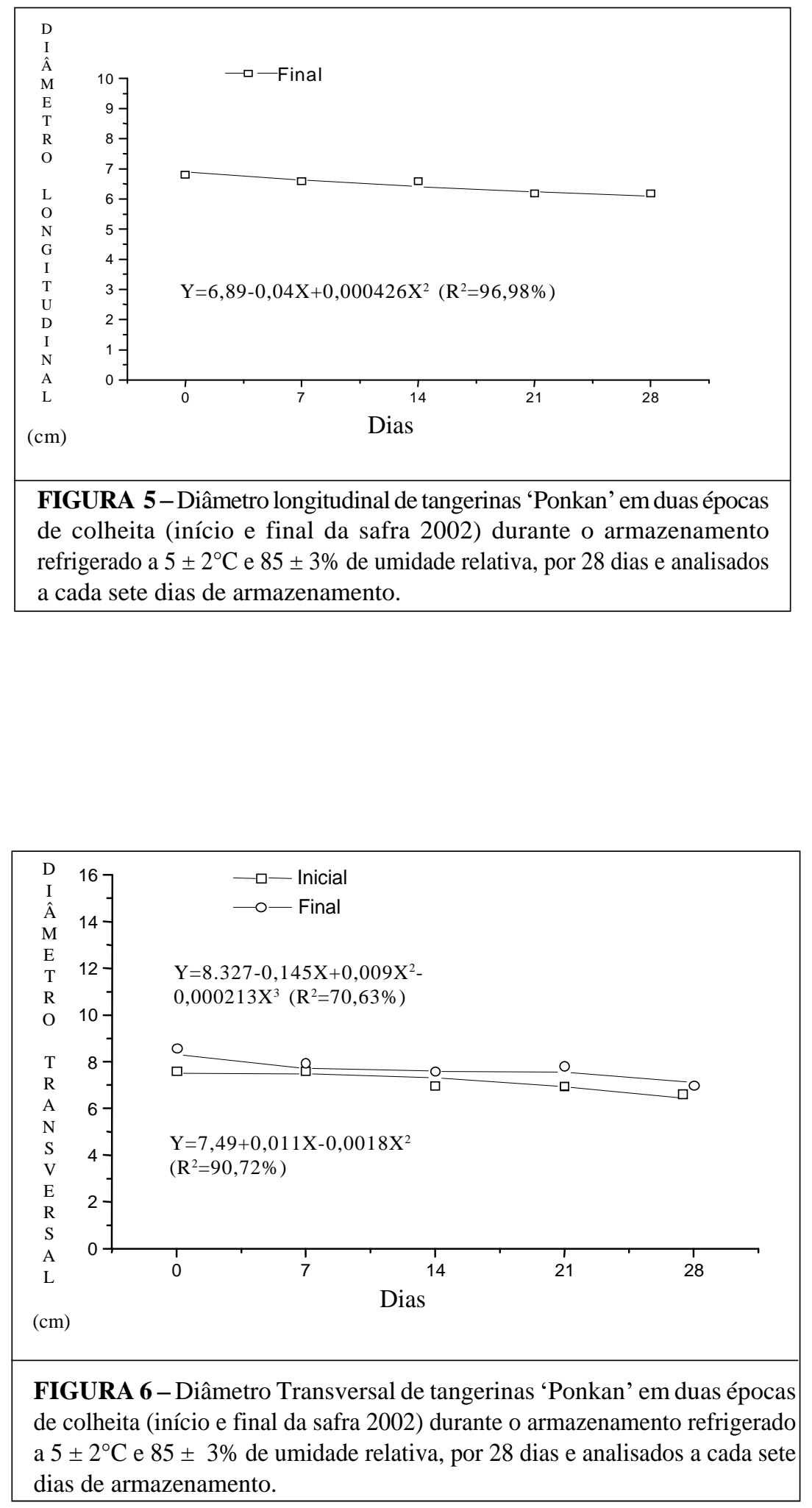

Ciênc. agrotec., Lavras, v. 30, n.4, p. 778-786, jul./ago., 2006 


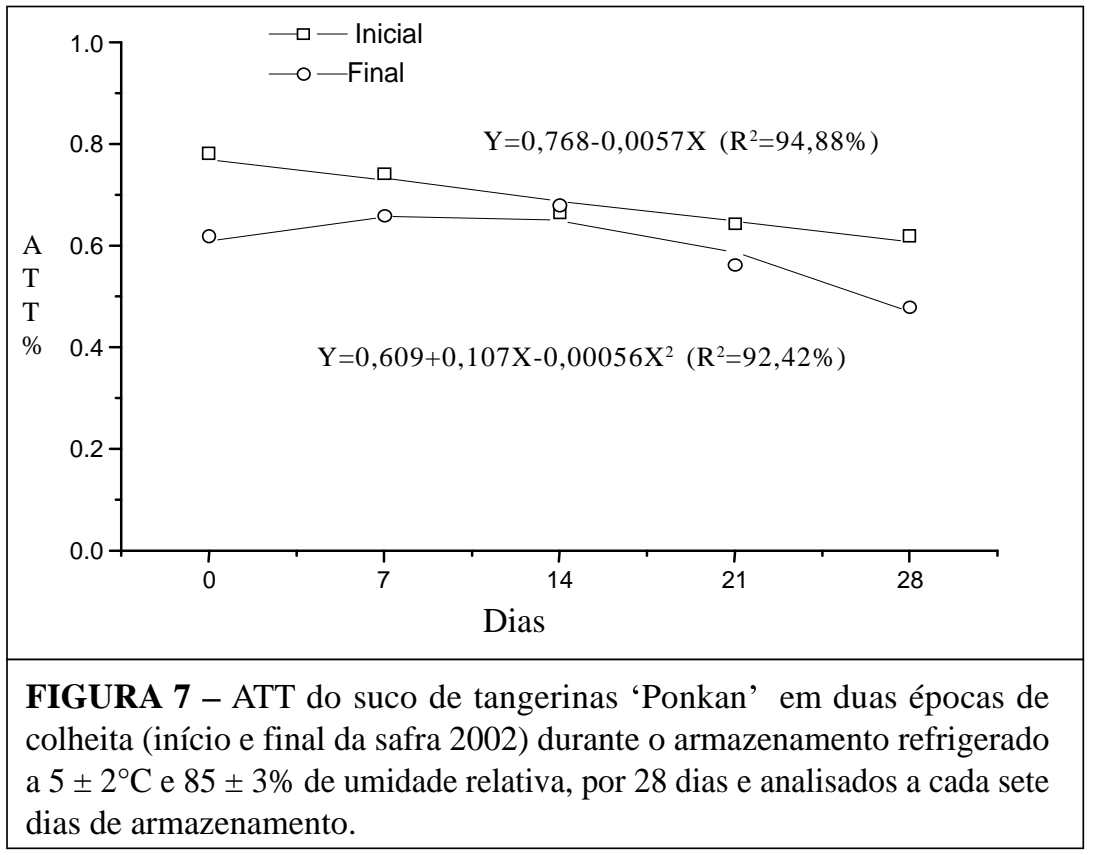

O teor de sólidos solúveis totais (SST) (Figura 8) apresentou uma ligeira variação durante o armazenamento com tendências de aumento com os dias de armazenamento. A colheita final apresentou maiores teores e também maiores variações do que a colheita inicial.

O teor de sólidos solúveis totais variou de 10,01 a $14,04^{\circ}$ Brix, estando de acordo com os valores encontrados por Chitarra (1979) e Silva (1999), que são da ordem de 7,5 a $16,2 \%$.

Holland (1998), ao observar tolerância de frutos cítricos a baixas temperaturas, citou que ocorre um acúmulo de açúcares tanto no suco como no flavedo do fruto. Porém, a evolução dos açúcares é distinta em ambas as partes do fruto. No suco se acumula principalmente sacarose, sendo que os aumentos em frutose e glicose são menores.

A variável Sacarose não apresentou variações significativas entre as colheitas, só houve alterações entre os dias de armazenamento refrigerado da colheita final. Podemos observar na Figura 9 um aumento progressivo dos teores de sacarose com os dias de armazenamento refrigerado na colheita final.

Os açúcares solúveis, tais como sacarose glicose e frutose têm sido indicados por uma maior tolerância de tomates ao frio. King et al. (1988) reportaram que altos níveis endógenos de sacarose, bem como as aplicações exógenas resultaram em maior tolerância ao frio. O aumento dos níveis de açúcares à temperatura baixa, de acordo com Purvis (1990), pode aumentar o turgor da célula e estabilizar membranas celulares e proteínas sob baixa disponibilidade de água.

A vitamina C não apresentou alterações significativas entre as colheitas e nem com os dias de armazenamento refrigerado.

Pelos resultados obtidos, nas condições que o experimento foi realizado pode se concluir que, durante o armazenamento refrigerado de tangerinas 'Ponkan'a $5^{\circ} \mathrm{C}$ e $85 \%$ de umidade relativa, coletadas em duas épocas ( Início e final da safra de 2002): Os frutos apresentaram perdas de peso significativas com o armazenamento refrigerado. Houve aumento nos teores de sólidos solúveis, sacarose e açúcares solúveis totais. A acidez diminuiu com os dias de armazenamento refrigerado.Não houve perdas significativas na vitamina $\mathrm{C}$ com o armazenamento refrigerado. A utilização do armazenamento refrigerado proporcionou a conservação das qualidades físicas dos frutos até a terceira semana de armazenamento.

Ciênc. agrotec., Lavras, v. 30, n. 4, p. 778-786, jul./ago., 2006 

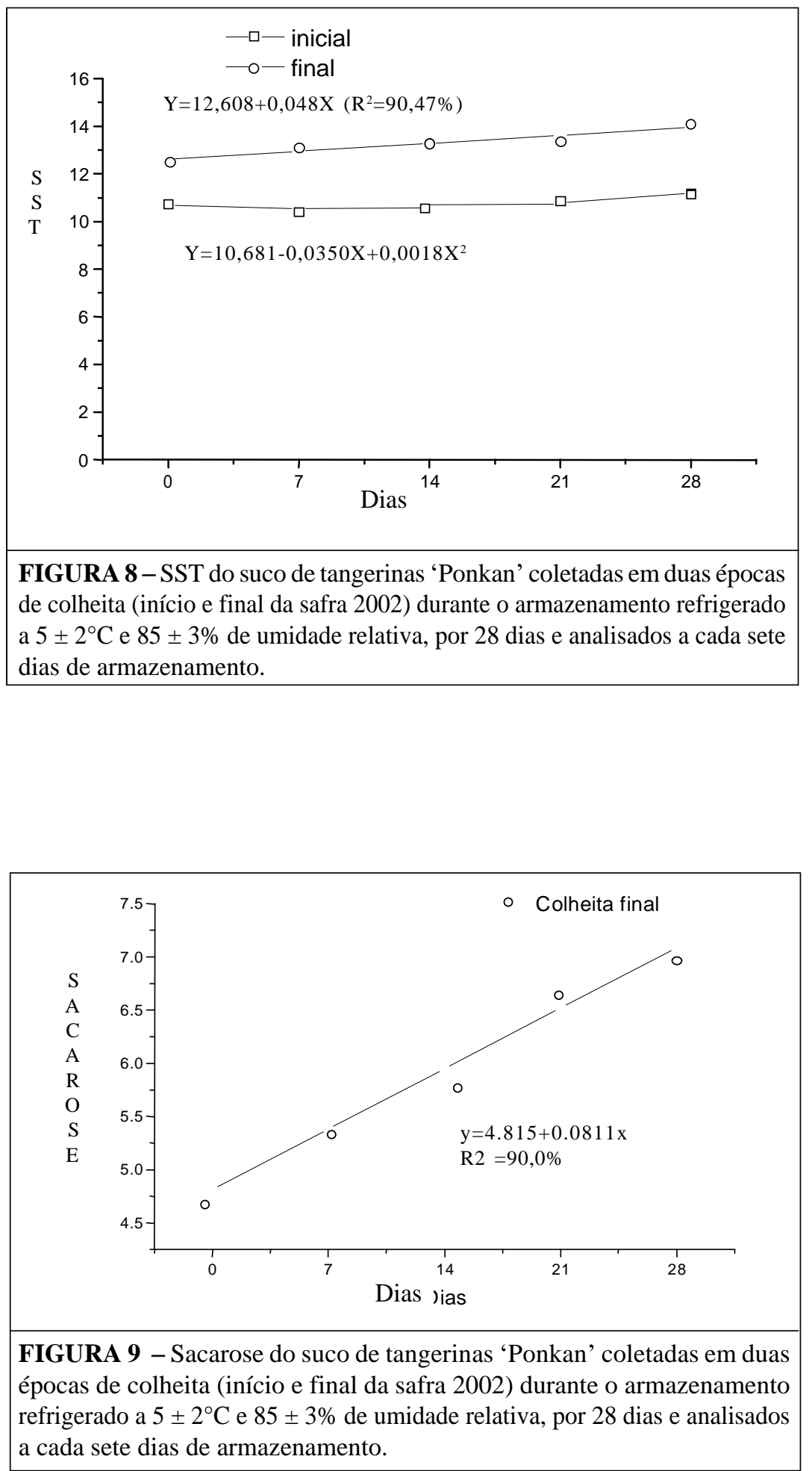

Ciênc. agrotec., Lavras, v. 30, n.4, p. 778-786, jul./ago., 2006 


\section{REFERÊNCIAS BIBLIOGRÁFICAS}

ASSOCIATION OF OFFICIAL ANALITICAL CHEMISTS. Official methods of analysis of the Association of official Analitical Chemists. 11. ed. Washington, 1992. 1115 p.

CHITARRA, M. I. F.Colheita e qualidade pós-colheita de citrus. Informe Agropecuário, Belo Horizonte, v. 17, n. 80, p. 45-51, 1994.

CHITARRA, M.I.F. Características físicas, físicoquimicas e químicas de alguns frutos cítricos cultivados em Minas Gerais: Ensaio com laranjas (Citrus Sinenis (1) Obseck) e tangerinas (Citrus reticulata Blanco) em fase de maturação. São Paulo: USP, 1979. 185p

CHITARRA, M. I. F.;CHITARRA, A. B. Pós-colheita de frutos e hortaliças: fisiologia e manuseio. Lavras: ESAL/ FAEPE, 1990. $320 \mathrm{p}$.

EMPRESA BRASILEIRA DE PESQUISA AGROPECUÁRIA. Embrapa. 2002. Disponível em: <http:/ i/Webombrapa.gov.bil' . Acesso em: 10 abr. 2003.

FIGUEIREDO, J. O. Variedades copa de sabor comercial. In: __ Citricultura brasileira. 2. ed. Campinas: Fundação Cargil, 1991. p. 228-264.

INSTITUTO ADOLFO LUTZ. Normas analíticas, métodos químicos e físicos para análise de alimentos. São Paulo, 1985. v. 1,533 p.

HOLLAND N. Metabolismo de carboidratos e a tolerância de frutos cítricos a baixas temperaturas. Tese de doutorado- Universidade Estadual de Campinas. Faculdade de Engenharia de Alimentos. 173p-1988

KADER, A. A. Posthaverst technology of horticultural crops. California: University of California, 1992. 296 p.
KING, A. I.; REID, M. S. Role of carbohydrates in diurnal chilling sensitivity of tomato seedlings. Plant Phisiology, v. 86, p. 764-768, 1988.

KOLLER, O. C. Citricultura: laranja, limão e tangerina. Porto Alegre: Ringel, 1994. 446 p.

NOELTING, G.; BERNFELD, P. Sur les enzymes amylolitiques 111. la b-amilase: dosage d'active et controle Iábsence d'a-amilase. Helvetica Chemica Acta, Basel, v. 31, p. 286-290, 1984.

PURVIS. A. C. Relation of chilling stress to carbohydrate composition. In: WANG, C. Y. Chilling injury of horticultural crops. Boca Raton: CRC, 1990. p. 211-221.

p-REIS, R. M. J. Relação entre o grau de coloração da casca e algumas características de qualidade de tangerina 'Ponkan'. Revista Ciência Agrotecnologia, Lavras, v. 24, p. 182-186, dez. 2000. Edição especial.

SILVA, P. A. M. Influência da lâmina de irrigação e área de umedecimento no crescimento e produção de tangor 'Murcote'. 1999. 117 p. Dissertação (Mestrado em Engenharia Agrícola) - Universidade Federal de Lavras, Lavras, 1999.

STROEKER, R.L. HENNING, H. M. Analisis de vitaminas: metodos comprobados. Madrid: Paz Montalvo, 1967, 482p.

TING, S. V.; ATTAWAY, J. A. Citrus fruits. In: The biochemistry of fruits and their products. London: Academic, 1971. v. 2, p. 107-169.

ULRICH, R. Organic acids. In: The biochemistry of fruits of fruits and their products. London: Academic, 1970. v. 1, p. 89-118. 